\title{
Cost effectiveness of a combination of instruments for global warming: a quantitative approach for Spain
}

\author{
M. C. Gallastegui • M. González-Eguino • \\ I. Galarraga
}

Received: 15 November 2010 / Accepted: 9 March 2011 / Published online: 29 March 2011

(C) The Author(s) 2011. This article is published with open access at SpringerLink.com

\begin{abstract}
Climate change is an important environmental problem and one whose economic implications are many and varied. This paper starts with the presumption that mitigation of greenhouse gases is a necessary policy that has to be designed in a cost effective way. It is well known that market instruments are the best option for cost effectiveness. But the discussion regarding which of the various market instruments should be used, how they may interact and what combinations of policies should be implemented is still open and very lively. In this paper we propose a combination of instruments: the marketable emission permits already in place in Europe for major economic sectors and a $\mathrm{CO}_{2}$ tax for economic sectors not included in the emissions permit scheme. The study uses an applied general equilibrium model for the Spanish economy to compute the results obtained with the new mix of instruments proposed. As the combination of the market for emission permits and the $\mathrm{CO}_{2}$ tax admits different possibilities that depend on how the mitigation is distributed among the economic sectors, we concentrate on four possibilities: cost-effective, equalitarian, proportional to emissions, and proportional to output distributions. Other alternatives to the $\mathrm{CO}_{2} \operatorname{tax}$ are also analysed (tax on energy, on oil and on electricity). Our findings suggest that careful, well designed policies are needed as any deviation imposes significant additional costs that increase more than proportionally to the level of emissions reduction targeted by the EU.
\end{abstract}

\footnotetext{
M. C. Gallastegui $(\varangle)$

Department of Economic Analysis I, University of the Basque

Country UPV-EHU, Bilbao, Spain

e-mail: mariacarmen.gallastegui@ehu.es

URL: http://www.ehu.es

M. González-Eguino · I. Galarraga

Basque Centre for Climate Change (BC3)-Klima Aldaketa Ikergai,

Bilbao, Spain

URL: http://www.bc3research.org
} 
Keywords Environmental policy instruments - Applied general equilibrium models $\cdot$ Cap and trade $\cdot \mathrm{CO}_{2}$ tax $\cdot$ Climate policy

JEL Classification $\quad \mathrm{D} 58 \cdot \mathrm{H} 21$

\section{Introduction}

Climate change (CC) is an important environmental problem. Its economic implications are many and varied. There is general agreement among economists that $\mathrm{CC}$ caused by anthropogenic actions can be modelled either as a public good (bad) of transnational scope or as a negative external effect (at world level) caused by the emission into the atmosphere of greenhouse gases (GHG). There is also agreement that (i) there are major scientific and economic uncertainties; (ii) the costs of controlling GHG will be borne in the present while benefits will accrue in future decades; and (iii) this kind of complexity raises a unique mix of problems. Many papers have focused on the economics of CC. Kolstad and Toman (2005), Stern (2008) and Nordhaus (2008) are good reviews of this literature. Microeconomic theory (Aldy et al. 2009; Tirole 2010), game theory (Uzawa 2003; Alesina and Passarelli 2010; Hoel 1990), macroeconomic models and many quantitative techniques (Weyant 1999; Springer 2003) also play important roles in the economics of CC.

Climate policy has become a hot topic. In the case of Europe, the European Union (EU) announced a Climate and Energy package with the following targets for 2020: reduce GHG emissions by $20 \%$ with respect to $1990,{ }^{1}$ reduce energy consumption by $20 \%$ through energy efficiency (EE) measures, and increase renewable energy production to $20 \% .^{2}$ This so called 20-20-20 package is based on three main specific policies: (1) a renewable energy policy; ${ }^{3}$ (2) an improved $\mathrm{CO}_{2}$ emission trading scheme (EU ETS) ${ }^{4}$ and (3) an 'Effort Sharing Decision' for emissions from sectors not covered by the EU ETS (referred to from now on as non-ETS sectors), such as transport, housing, agriculture and waste (Gallastegui and Galarraga 2010).

Of the main market instruments used to date the trading scheme is the most important. After an initial trial period (2005-2007) and with the lessons learnt during the ongoing 2008-2012 period, the new "market permit" scheme contains several changes that could significantly improve the economic efficiency of the system. ${ }^{5}$ But the

\footnotetext{
1 With the possibility of this target being raised to $30 \%$ if other developed countries agree on ambitious targets.

2 Including a target of $10 \%$ renewable energy in the transport sector. This additionally includes decisive support for carbon capture and storage (CCS) technologies included under the general heading of Geo-engineering solutions.

3 Supported by the Directive (2009/28/EC).

4 Backed up by the "new" Directive (2009/29/EC). The EU ETS covers mainly power stations and other combustion plants, oil refineries, coke ovens, iron and steel plants and factories making cement, glass, lime, bricks, ceramics, pulp and paper and cardboard. The aviation sector is also to be included.

5 They include increasing auctioning ( $100 \%$ by 2013 for the electricity sector, and for the rest $20 \%$ by $2013,70 \%$ by 2020 and $100 \%$ by 2027), the use of a sectoral approach for the distribution of rights by the European Commission (eliminating allocation by Member States through National Allocation Plans) and
} 
European Commission ${ }^{6}$ has also established binding targets for the efforts required of each Member State in sectors not regulated by the EU ETS. In the case of Spain, the target is a $10 \%$ reduction on 2005 levels. ${ }^{7}$ Member States have some freedom to decide how these targets will be met. This is thus an excellent opportunity to discuss what instruments could be used to achieve these objectives, how they may interact and what combinations of policy instruments could be implemented.

The research community has been putting great effort into designing effective policy instruments for environmental policy. The literature on the choice of market-based instruments versus command and control instruments is mature and well developed (Weitzman 1974; Baumol and Oates 1988; Hahn 1989, 2000; Tietenberg 1990; and others). In the economics literature it is also quite clear what a "cost effective policy instrument" means: it is one which is capable of attaining the desired environmental target level at the minimum cost. In the case of mitigation policies, cost effectiveness implies that all economic agents must pay the same price, at the margin, for their emissions (Baumol and Oates 1971). Additionally, it is well established that when markets are perfect emission trading permits and $\mathrm{CO}_{2}$ tax that covers all sources of emissions can both achieve the reductions at minimum cost (Weitzman op cit). Parry and Pizer (2007) show that the main issue is not the choice of instrument per se but rather how instruments are designed, given that under certain conditions both instruments can be designed to achieve similar outcomes. Other papers such as Hauser et al. (2008) and Hourcade et al. (2008) deal with how both instruments can harm competitiveness, while Green et al. (2007) highlights that carbon taxes can help to eliminate other distortionary taxes. There is also a considerable body of literature that discusses policy instruments in terms of cost effectiveness and dynamic efficiency (Goulder et al. 1999; Hoel and Karp 2002). But beneath this general agreement there are many specific questions in which no consensus has yet emerged. For instance, work has been done at the theoretical and empirical levels on the analysis of different evaluation criteria for instruments (Goulder and Parry 2008) and also on the possible effects of combining different types of policies, either horizontally (in the same jurisdiction) or in different jurisdictions (Goulder and Stavins 2010).

In fact, one could argue that the combination of instruments is the most sensible way to simultaneously achieve different policy goals. This is especially true in the case of GHG emissions (where there are multiple emission sources) if ambitious targets are to be met at reasonable cost (OECD 2009). ${ }^{8}$ On this respect, Ansuategi and Galarraga (2009) review the literature on carbon taxes versus carbon trading and propose a combination of the two instruments in a hybrid system, in line with the recommendation by Newell and Stavins (2003). Several authors have dealt with interactions between

\footnotetext{
Footnote 5 continued

an increase in the number of economic sectors and GHGs included in the scheme. The number of distorting elements in the policy designed is greatly reduced.

6 COD (2008).

7 As a consequence, an additional reduction of 25 million tons of GHG emissions is required.

8 Furthermore, the OECD highlights that "[...] carbon taxes or emissions trading schemes turn out to be more effective and comprehensive than other policy tools. However, their cost-effectiveness could be enhanced by complementing them with other instruments to create a mixed climate policy package".
} 
EU ETS and national policies (Del Río 2009; Boots 2003; Sijm 2005; Sijm 2003; Morthorst 2003).

Finally, in the case of Spain, Del Río (op cit; 2008), Del Río et al. (2009), Linares et al. (2008) look specifically at the interaction of policies, while González-Eguino (2010) deals with the economic impact of $\mathrm{CO}_{2}$ mitigation and Labandeira and Rodríguez (2007) consider distributional issues. Other interesting pieces of research include Manresa and Sancho (2005) for environmental tax reforms.

This paper fits into the context of the new European climate policy explained earlier, and more specifically into the setting up of national targets for non-ETS sectors (the "Effort Sharing Decision"). In particular, the work presented here computes the mitigation costs of a new policy mix: the combination of carbon trading (EU ETS) and a $\mathrm{CO}_{2}$ tax for non-ETS sectors. Other tax options are also considered. The specific issues analysed are: (1) what are the impacts of different distribution of mitigation efforts between ETS and non-ETS sectors?; and (2) for the latter what are the implications of using energy, oil and electricity taxes besides the $\mathrm{CO}_{2}$ tax? The study uses an applied general equilibrium (AGE) model for the Spanish economy. ${ }^{9}$ To the best of our knowledge, the effects of this policy mix have not been computed to date for any European economy.

The rest of the paper is organised as follows: Sect. 2 presents the scenarios proposed; Sect. 3 presents the AGE model and Sect. 4 presents the results. The conclusions and some ideas on further research are given in Sect. 5.

\section{Scenarios}

For the first issue, that is, the impacts of different distribution of mitigation efforts between ETS and non-ETS sectors, the following four different effort sharing distributions are considered:

1. Cost-effective Distribution (CED): CED defined as a distribution in which emission reductions are obtained in sectors where marginal costs of abatement are lower and marginal costs of abatement are equalised among sectors. In this case, in the context of an AGE model, a market for tradable emission permits or a tax on $\mathrm{CO}_{2}$ for all emission sources will produce the same resource allocation. Note that in this scenario shares are not exogenously imposed but are obtained endogenously by the model.

2. Equalitarian Distribution (ED): This scenario analyses a situation in which half of the mitigation target is met by ETS sectors and the other half by non-ETS ones.

3. Proportional Emission Distribution (PED): The effort is distributed according to the share of real emissions between ETS and non-ETS sectors in a baseline year. In our data base emissions in the ETS sector account for $44 \%$ of the total.

4. Proportional Output Distribution (POD): The effort is distributed according to the share of national output accounted for by each sector in a baseline year. In our case ETS represents only $10 \%$ of national output.

\footnotetext{
9 Böhringer and Rosendahl (2010) argue that AGE models are the most appropriate models to quantify the impacts and interactions of different policy instruments.
} 
These share rules are very common and have been applied (or at least defended) in many different policy contexts by different groups, sectors or countries. For example, all these rules have been suggested or applied in climate policy when designing National Allocations Plans (see for example: Sijm 2007 or Arto et al. 2009) or also in other context such as fisheries, when sharing the total allowable catch (TAC) among countries (see for example: Gallastegui et al. 2002).

For the second issue, the paper explores the possibility of not taxing $\mathrm{CO}_{2}$ emissions directly but rather taxing actions close to emissions because of the diffuse, shifting nature of many sources and sectors (services, residential, transport). In fact, after the political and administrative process takes place, taxes are usually very different from what is recommended in textbooks ${ }^{10}$ (Pearce 2006). The following tax options are analysed for non-ETS sectors, assuming that ETS sectors continue to be covered by the EU ETS and that the share of the burden achieved is cost effective (i.e. the one suggested by the CED scenario):

1. Energy Tax: This is a tax on consumption of coal, refined oil and gas from non-ETS sources (including consumers). It does not take into account the different carbon contents of each fossil fuel, so the rate is the same for all three.

2. Oil Tax: This is a tax on consumption of refined oil from non-ETS sources (including consumers).

3. Electricity Tax : This is a tax on consumption of electricity from non-ETS sources (including consumers). Although electricity consumption does not directly emit $\mathrm{CO}_{2}$, its production is fossil-fuel intensive, and accounts for $22.7 \%$ of total $\mathrm{CO}_{2}$ emissions. A reduction in consumption of electricity in non-ETS will indirectly reduce emissions.

Of course, there are many other possibilities that could be analysed such as a tax on coal or on natural gas. These instruments however only attain very small reductions in emissions if imposed in non-ETS sectors, so they have not been considered.

\section{The model}

To estimate the mitigation costs of the different climate policy designs we use a static version of an AGE model (see Appendix for notation). These models are empirical versions of a Walrasian model which enable interdependencies between different economic agents to be taken into consideration (Shoven and Whalley 1992). They are useful for analysing policies such as climate policies, which generate significant direct and indirect impacts.

The tradable emission market is simulated following Dellink et al. (2004) approach. The government sets the number of permits for each period and allows them to be traded freely on the market. Permits are, thus, modeled as a production factor (linked directly to $\mathrm{CO}_{2}$ emissions) whose price is determined in equilibrium (the number of permits decided by the authority determines its supply). Sectors have to pay for all

\footnotetext{
10 In fact, Pearce shows in this study that the UK Climate Change Levy generates an "implicit carbon tax" in which natural gas, which has the lowest carbon content, has the highest tax rate. This paradoxically generates an incentive to replace gas by coal.
} 
the permits used the market price. In contrast, the tax simulation process is based on an iterative process in which taxes are increased gradually until the desired level of emission reductions is achieved. The revenue obtained with any of the instruments included in the simulations (taxes or permit market with) is channeled to representative consumers via transfers (i.e. an equal yield tax reforms) so government expending remains constant (see Sect. 3.6). For the sake of simplicity, this paper assumes that all reductions have to be achieved mainly though these two policies, that is, no other related policies are considered. Specifically, this means that no additional emission permits can be bought outside the EU borders.

Three classes of conditions have to be fulfilled in a competitive equilibrium: zero profit conditions, market clearance conditions and income balance conditions. Equilibrium is characterised by a set of equilibrium prices such that demand equals supply for all commodities simultaneously (market clearance condition). In this situation agents cannot do better by altering their behaviour. Differentiating the profit and utility functions with respect to input and output prices provides compensated demand and supply coefficients (Shephard's lemma), which appear subsequently in the market clearance conditions. For the sake of simplicity, and as it is usual in this field, we do not write down the explicit functional forms but instead use the acronyms: LT (Leontief); CD (Cobb-Douglas), CES (Constant Elasticity of Substitution) and CET (Constant Elasticity of Transformation) to indicate the class of functional form in place. For more explanations about this type presentation of AGE models see Dellink et al. (2004) or Faehn et al. (2009).

The model comprises (1) 22 production sectors; (2) a representative consumer; (3) a government which collects taxes, supplies goods and services and controls $\mathrm{CO}_{2}$ emissions through the different instruments proposed; and (4) the "Rest of the World", an aggregate that brings together the foreign sector. Production sectors are broken down into energy sectors (coal, oil, gas and electricity), major emitters (industry and transport) and other sectors with major economic weight (public and private services).

\subsection{Producers}

Each production sector $j=1, \ldots J$ produces a homogenous good with a technology characterised by nested CES functions. The output of each sector $\left(Y_{i}\right)$ is obtained by combining the intermediate inputs $\left(Y_{1, j}^{I D}\right)$ capital $\left(K_{j}\right)$ and labour $\left(L_{j}\right)$. Equation $1^{11}$ shows a simplified form of this output function, and Fig. 1 depicts its structure in graphic form. The sigma parameters $(\sigma)$ of the function represent the elasticities of substitution between different inputs (see Appendices). Finally, when a $\mathrm{CO}_{2}$ market instrument is simulated permits should also be included in the function $\left(E_{j}^{P}\right)$ as another production factor that is needed. It is directly linked with a specific coefficient (with

11 Equation 1 depicts these functions in a shortened form, via inputs and elasticities. For instance, a CES function for a case with two levels of nesting and two inputs takes the following form: on the first level: $Y=$ $\operatorname{CES}\left(X_{1}, X_{2} ; \sigma\right)=\left(a_{1} X_{1}^{\sigma-1 / \sigma}+a_{2} X_{2}^{\sigma-1 / \sigma}\right)^{\sigma / \sigma-1}$ and on the second level: $X_{2}=\operatorname{CES}\left(X_{3}, X_{4} ; \psi\right)=$ $\left(a_{3} X_{3}^{\psi-1 / \psi}+a_{4} X_{4}^{\psi-1 / \psi}\right)^{\psi / \psi-1}$, where $\mathrm{a}_{1}, \mathrm{a}_{2}, \mathrm{a}_{3}, \mathrm{a}_{4}$ are parameters and $\sigma, \psi$ represent the elasticities of substitutions between the inputs. By substituting $X_{2}$ in function $Y$ we can envisage the length of the output functions proposed. 


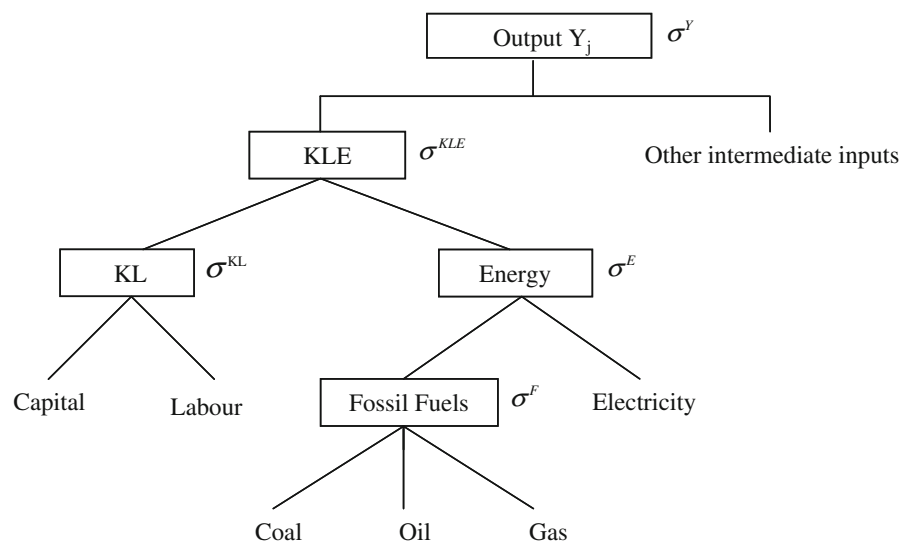

Fig. 1 Output function structure. Source Babiker et al. (2001)

Leontief function) to the consumption of coal, oil and gas $\left(Y_{e, j}^{I D}\right)$.

$$
Y_{j}=C E S\left(Y_{1, j}^{I D}, \ldots, Y_{J, j}^{I D}, K_{j}, L_{j}, E_{j}^{P}: \sigma\right), \quad \forall j \in(1, \ldots, \mathrm{J})
$$

Producers maximise profit, subject to the technological constraints. At equilibrium, net profit after tax would be zero, i.e. the value of the output from each sector would be the same as the sum total value of the inputs. This condition is reflected in Eq. 2, where $P_{j}$ is the price of the output from sector $j, P_{K}$ is the price of capital and $P_{L}$ is the price of labour. $\tau_{j}^{K}$ and $\tau_{j}^{L}$ are the sectoral tax rates on capital and labour. Finally, when a $\mathrm{CO}_{2}$ instrument is implemented (with a $\mathrm{CO}_{2}$ emission permit market or a $\mathrm{CO}_{2}$ price) the producer has to pay (directly or indirectly) a market price $\left(P_{E}\right)$ for every unit of permit/emissions used or $\left(E_{j}^{P}\right)$. However, when a non- $\mathrm{CO}_{2}$ tax instrument is implemented the producer has to pay a $\operatorname{tax}\left(\tau_{*}^{T}\right)$ on the consumption of the specific energy-related inputs selected for taxation $\left(Y_{*, j}^{I D}\right.$, where $*$ can refers to coal, oil, electricity or any other input).

$$
\begin{aligned}
& \sum_{j j=1}^{J} Y_{j j, j}^{I D}\left(P_{j}+\tau_{*}^{T}\right)+\left(P_{K}+\tau_{j}^{K}\right) K_{j}+\left(P_{L}+\tau_{j}^{L}\right) L_{j}+P_{E} E_{j}^{P} \\
& \quad=Y_{i} P_{j}, \quad \forall j \in(1, \ldots, \mathrm{J})
\end{aligned}
$$

\subsection{Consumers}

The model considers a representative consumer, who owns the production factors. Consumer preferences are defined by a utility function from among the various consumer goods $j$ and their corresponding elasticities of substitution (see Eq. 3 and Fig. 2).

$$
U=C E S\left(C_{1}, \ldots, C_{J}: \sigma\right)
$$

The consumer maximises his total utility (U) subject to his budgetary constraints. As shown in Eq. 4, the income obtained from labour, capital and direct transfers 


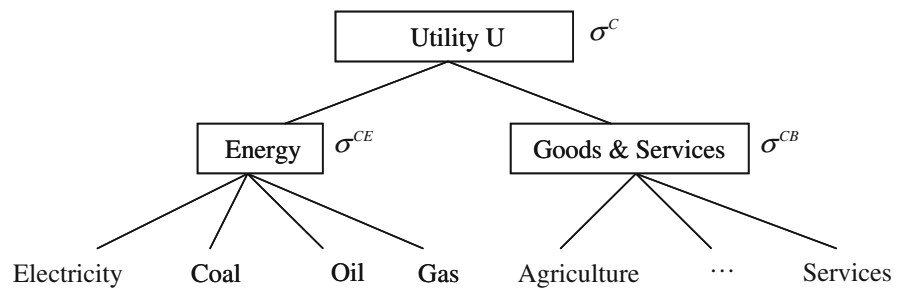

Fig. 2 Utility function structure. Source Babiker et al. (2001)

from the government $(T)$ is equal to consumption $\left(C_{j}\right)$, tax payments associated with consumption $\left(\tau_{j}^{C}\right)$ and savings $(S)$. The savings of the representative consumer (see Sect. 3.7) are what enable investments and the foreign trade deficit to be financed.

$$
P_{K} \cdot K+P_{L} \cdot L+T=\sum_{j=1}^{J}\left(P_{j}+\tau_{j}^{C}\right) \cdot C_{j}+S
$$

\subsection{The government}

The government obtains its income through taxes on capital, labour and consumption. That income enables it to provide public goods and services $G_{j}$ and make direct transfers to consumers $(T)$. The preferences of the government are modelled via a Leontief function that enables the structure of public spending to be considered as fixed (see Eq. 5).

$$
\begin{gathered}
\bar{G}=L T\left(G_{1}, \ldots, G_{J}\right) \\
\sum_{j=1}^{J}\left(\tau_{j}^{L} \cdot L_{j}+\tau_{j}^{K} \cdot K_{j}+\tau_{j}^{C} \cdot C_{j}\right)=\sum_{j=1}^{J} P_{j} \cdot \bar{G}_{j}+T
\end{gathered}
$$

The additional income collected by the government from $\mathrm{CO}_{2}$ market or taxes is transferred directly $(T)$ to consumers, so that the level of public spending remains constant (see Eq. 6). In the case of the $\mathrm{CO}_{2}$ market instrument this extra income will be determined by multiplying all the permits by the market price $\left(\sum_{j=1}^{J} P_{E} E_{j}^{P}\right)$. In the case of the tax instrument, it will be determined by multiplying $\mathrm{CO}_{2}$ or specific energy-related inputs by the $\operatorname{tax}\left(\sum_{j=1}^{J} \tau_{*}^{T} Y_{*, j}^{I D}\right)$

\subsection{The foreign sector}

To reflect trade with surrounding areas, we group all other countries into a single aggregate item referred to as the "Rest of the World". Out of all the flows that exist, we consider imports and exports of goods and services.

Two assumptions habitually made in AGEs are used here. The first is the small economy assumption, which establishes that (a) the domestic economy is too small 
to influence world-wide prices; and (b) import and export requirements can be met by trade with the Rest of the World. The second is the Armington assumption, which assumes that domestic and imported/exported goods are imperfect substitutes. In practice, this means modelling total supply $\left(Y_{j}^{T S}\right)$ as a CES function (see Eq. 7) which aggregates domestic output $\left(Y_{j}\right)$ and imports $\left(M_{j}\right)$; and total demand $\left(Y_{j}^{T D}\right)$, equal to total supply, by means of a transformation function or CET function (see Eq. 8), which breaks down that aggregate into domestic demand $\left(Y_{j}^{D}\right)$ and exports $\left(X_{j}\right)$.

$$
\begin{aligned}
Y_{j}^{T S} & =\operatorname{CES}\left(Y_{j} ; M_{j}\right), \quad \forall j \in(1, \ldots, \mathrm{J}) \\
Y_{j}^{T D} & =Y_{j}^{T S}=\operatorname{CES}\left(Y_{j} ; X_{j}\right), \quad \forall j \in(1, \ldots, \mathrm{J})
\end{aligned}
$$

Finally, as a "closure rule" (see Eq. 9), we assume that the trade deficit $(X D)$, i.e. imports minus total exports, is constant, with $P_{X}$ being the adjustment variable.

$$
\sum_{j=1}^{J} P_{X}\left(M_{j}-X_{j}\right)=\overline{X D}
$$

\section{$3.5 \mathrm{CO}_{2}$ emissions}

$\mathrm{CO}_{2}$ emissions are calculated by using coefficients $\left(\alpha_{e}, \lambda_{e}\right)$ applied to consumption of coal, oil and gas. The representative consumer also generates emissions (heating, gasoline and diesel, etc.) so the total emissions $(E)$ are the sum of the emissions from the production sectors $j\left(E^{P}\right)$ and those of the representative consumer $\left(E^{C}\right)$

$$
E=E^{P}+E^{C}=\sum_{j=1}^{j} \sum_{e=1}^{3} \alpha_{e} \cdot Y_{e, j}^{I D}+\sum_{e=1}^{3} \lambda_{e} \cdot C_{e}
$$

The potential for emission reduction is limited, because burning fossil fuels inevitably generates $\mathrm{CO}_{2}$. However, in the context of this model, emissions can be reduced in an induced fashion. When emissions are limited the relative prices of the factors vary, resulting in changes (i) in the energy mix, with $\mathrm{CO}_{2}$ intensive fossil fuels being replaced by less intensive fuels; (ii) in the output and utility functions, with energy use being replaced by other inputs; and (iii) in the economic structure, with patterns of consumption shifting towards low-carbon products and services. Finally, once all the possibilities of substitution have been exploited, the alternative that remains is to reduce the output in some sectors.

\subsection{Supply of capital and labour}

The total supply of labour is considered to be exogenous. However, it is important to specify investment and capital flows: the level of investment in an economy depends on interest rates, on the capital stock and on depreciation. These points cannot be incorporated into a static context, so we assume that the initial capital stock is adjusted 
over the years of the simulation in line with the following condition: the price of investment $\left(P_{I}\right)$ in equilibrium must be equal to the price of capital $\left(P_{K}\right)$. In this way (Hayashi 1982), investment decisions are at least consistent with the return required by capital.

\subsection{Equilibrium and solution}

The conventional Walrasian concept of equilibrium is used: the quantities supplied are equal to the quantities demanded, prices act as adjustment variables and all agents comply with their optimisation plans. In our case, that means equilibrium in the goods and services markets (Eq. 11), in the labour and capital markets (Eqs. 12 and 13) and between savings and investment (Eq. 14). In the case of instruments that use a tradable emission permit market there is also equilibrium between the permits supply by the government and those demanded by agents, by setting a price for those permits

$$
\begin{gathered}
Y_{j}^{D}=\sum_{j j=1}^{J}\left[Y_{j, j j}^{I D}\right]+C_{j}+G_{j}+I_{j}+\left(M_{j}-X_{j}\right), \quad \forall j \in(1, \ldots, \mathrm{J}) \\
\sum_{j=1}^{J} L_{j}=\bar{L} \\
\sum_{j=1}^{J} K_{j}=\bar{K} \\
S=\sum_{j=1}^{J} P_{j} \cdot I_{j}+\overline{X D} \\
\bar{E}=E^{E T S}
\end{gathered}
$$

Finding equilibrium solutions requires solving a system of non-linear equations. The model is programmed using GAMS/MPSGE and resolved with the PATH algorithm.

\subsection{Calibration and data}

The initial equilibrium data come from an SAM drawn up by integrating ${ }^{12}$ the data from the Symmetric Input Output Table (INE 2002, see Table A1) and the data from sectoral energy balance sheets (Eurostat 2005). The integration of these two tables reveals the underlying energy flows in the IOT, so that $\mathrm{CO}_{2}$ emissions can then be

\footnotetext{
12 Energy data are integrated by introducing new rows into the IO Table for demand for energy goods (crude oil, coal, Oil, gas and electricity) originating from the multiplication of the physical data and prices for energy balance sheets using the procedure described in Rutherford and Paltsev (2000).
} 
calculated. ${ }^{13}$ The reaction of agents to changes is reflected through elasticities of substitution (Babiker et al. 2001; see Table A2) and emissions are calculated via the standard coefficients ${ }^{14}$ for coal, oil and gas.

\section{Results}

This section presents the results for the different scenarios presented in Sect. 2. To analyse the different performances, each scenario simulates and compares identical reductions in $\mathrm{CO}_{2}$ emissions. We discuss the results obtained from analysing different ways of implementing a given reduction of emissions from 5 to $40 \%$. In the first place, the differences in implementation refer to the use of different criteria for distributing the burden of the emission target between ETS and non-ETS sectors. Secondly, we discuss the impacts of using different types of tax in non-ETS sectors, assuming that the effort share supported by each subset of sectors is that which results from the CED (i.e. the cost-effective) scenario.

\subsection{General results for different emission reductions in ETS and non-ETS sectors}

Figure 3 shows the link between $\mathrm{CO}_{2}$ reduction and gross domestic product (GDP) for the various scenarios listed in Sect. 2. It comes as no surprise that the cost of emission reductions in terms of GDP differs substantially depending on how the policy is designed. Different outcomes are obtained when mitigation efforts are shared differently between ETS and non-ETS sectors. Our quantitative results show that the relationship between emission reductions and reductions in GDP is convex, i.e. the cost of reduction increases more than proportionally as the level of reductions increases. This effect is a consequence of the fact that the best mitigation options are usually used first and when the level of emission reductions increases these best mitigation options are exhausted.

The CED scenario is the benchmark option as it achieves the target at minimum cost. It could be denoted as the "most suitable option" in this second best context. Note that although some of the scenarios are very close to the CED in terms of costs for low levels of $\mathrm{CO}_{2}$ reduction, the differences increase (in a non linear way) when the reduction of emissions increases. For example, with a $20 \%$ reduction in emissions the macroeconomic impacts of the CED, ED and POD scenarios are very similar, and GDP losses are $0.35,0.43$ and $0.46 \%$ respectively. But with a $40 \%$ reduction in emissions the differences increase considerably to $1.07,1.2$ and $3.06 \%$. As more mitigation effort is made the differences between methods increase and which of the options considered in this paper is chosen becomes a crucial factor.

\footnotetext{
13 The database used to draw up the SAM is the symmetric IO Table of the INE (Spanish National Statistics Office), so the data are valued at basic prices. Tax on consumption includes VAT and the tax on labour includes social security contributions payable by workers. All remaining taxes are grouped under tax on capital.

14 As SAM cannot distinguish between quantities and prices, so different emission coefficients are assumed that reflects the difference in prices paid by consumers and producers for energy products. However, the physical emission coefficients used are the standard used by Eurostat (2005): tonnes of $\mathrm{CO}_{2}$ per Ktoe for coal (4.104), oil (2.851) and gas (2.187).
} 


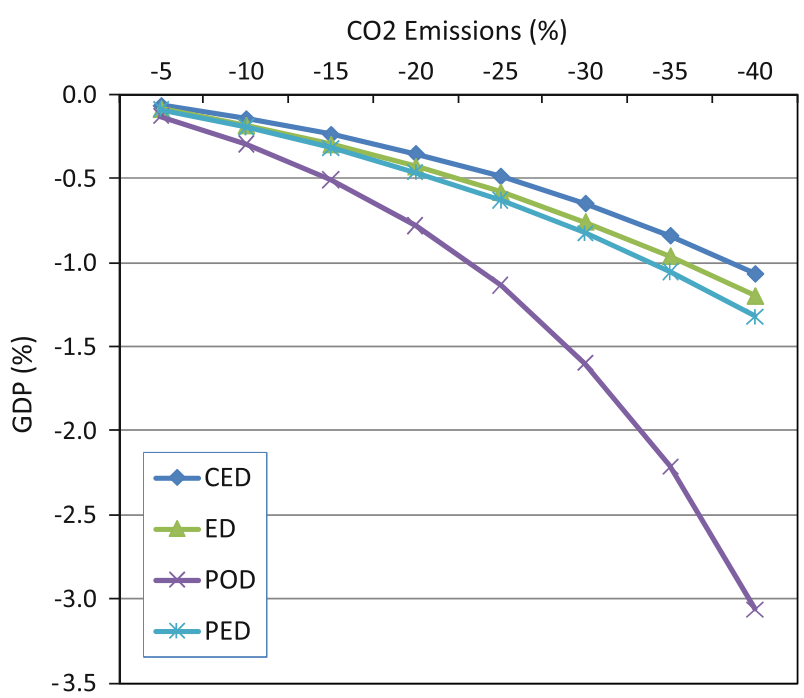

Fig. 3 Total $\mathrm{CO}_{2}$ emission reduction and costs for different scenarios

Table 1 Cost-effective share-out of reduction effort

\begin{tabular}{lllllllllll}
\hline & $5 \%$ & $10 \%$ & $15 \%$ & $20 \%$ & $25 \%$ & $30 \%$ & $35 \%$ & $40 \%$ & $45 \%$ & $50 \%$ \\
\hline ETS & 0.71 & 0.70 & 0.69 & 0.68 & 0.66 & 0.65 & 0.63 & 0.62 & 0.60 & 0.59 \\
Non ETS & 0.29 & 0.30 & 0.31 & 0.32 & 0.34 & 0.35 & 0.37 & 0.38 & 0.40 & 0.41 \\
\hline
\end{tabular}

It is also worth comparing the ED and PED scenarios. Both generate aggregate impacts that are not far from the CED. To understand why this happens, consider the cost-effective share, implicitly obtained from the CED scenario (see Table 1). This table shows how the reductions are shared between ETS sectors and non-ETS when mitigation is achieved cost-effectively. Note that for low emission reduction targets ETS sectors should make around $71 \%$ of the total effort but when targets are higher and the cheapest abatement options for ETS sectors are exhausted, their share gradually drops to 59\%. In the ED scenario the share of ETS is 50\% and constant, while in POD it is $45 \%$. Therefore, we can conclude that ED is always a better choice than PED as cheaper abatement options are available when the ED scenario is used.

In other words it can be noted that in the ED scenario there are two important differences: first the magnitude of the shares between ETS and non-ETS sector is larger and second, these magnitudes remain constant independently of the level of effort made in emission reduction. Aggregate costs, as expected, are greater than in the CED scenario and the difference between the two alternatives slowly increases with the level of reduction effort. That is, deviations from the cost-effective way of implementing emission reductions are not only costly but increase with the level of effort. The same conclusion holds in the PED scenario.

Finally, in the POD scenario the cost of cutting emissions proves extremely high. If the emission reduction targets were distributed according to each sector's contribution to output the cost would rocket, as the drop in GDP would be $0.78 \%$ for a 
Table $2 \mathrm{CO}_{2}$ emission permit price and tax on $\mathrm{CO}_{2}\left(€ / \mathrm{tCO}_{2}\right)$ for different scenarios

\begin{tabular}{lrrrrrrrrrr}
\hline & $5 \%$ & $10 \%$ & $15 \%$ & $20 \%$ & $25 \%$ & $30 \%$ & $35 \%$ & $40 \%$ & $45 \%$ & $50 \%$ \\
\hline CED & 2.1 & 4.5 & 7.5 & 11.0 & 15.2 & 20.3 & 26.6 & 34.5 & 44.3 & 56.8 \\
ED & & & & & & & & & & \\
$\quad$ ETS & 1.3 & 2.8 & 4.6 & 6.7 & 9.1 & 12.0 & 15.6 & 20.0 & 25.5 & 32.7 \\
$\quad$ Non ETS & 4.0 & 8.5 & 13.8 & 19.9 & 27.0 & 35.4 & 45.2 & 56.9 & 70.9 & 87.8 \\
POD & & & & & & & & & & \\
$\quad$ ETS & 0.1 & 0.2 & 0.5 & 0.8 & 1.0 & 1.2 & 1.5 & 1.7 & 2.0 & 2.3 \\
$\quad$ Non ETS & 7.8 & 18.0 & 31.4 & 49.3 & 74.1 & 109.1 & 161.1 & 243.4 & 386.7 & 680.1 \\
PED & & & & & & & & & & \\
$\quad$ ETS & 1.1 & 2.4 & 3.8 & 5.5 & 7.4 & 9.5 & 12.1 & 15.1 & 18.7 & 23.2 \\
$\quad$ Non ETS & 4.5 & 9.7 & 15.9 & 23.3 & 32.0 & 42.5 & 55.2 & 70.8 & 90.0 & 114.2 \\
\hline
\end{tabular}

$20 \%$ cut in emissions and $3.06 \%$ for a $40 \%$ cut. The explanation again depends on the same rationale. The cheapest mitigation options would have to be ruled out as the effort (share) assigned to ETS sectors is very low. Furthermore, the industries affected (mainly transport and services) have major indirect impacts which feed back negatively into the economy as a whole.

Another way of analysing the cost of emission reduction is by looking at the prices for $\mathrm{CO}_{2}$ in each scenario. Table 2 shows the $\mathrm{CO}_{2}$ prices (in the form of a price for emission permits or in the form of a tax on $\mathrm{CO}_{2}$ ) that are needed to achieve the reduction target in each scenario. In the CED scenario the minimum price needed to achieve a reduction in emissions in the interval 5 to $50 \%$ ranges from $2.1 €$ to $56.8 € / \mathrm{tCO}_{2}$. A comparison of the prices obtained in the ED and PED scenarios with those obtained using CED reveals that prices for emission permits are always too low for ETS sectors and too high for non-ETS. The explanation is obvious: the distribution of emission reductions between the two blocks is not cost-effective (Table 1). When the POD scenario is used the equilibrium price in the $\mathrm{CO}_{2}$ market is very low (below $2 € / \mathrm{tCO}_{2}$ ) as the emission targets for ETS sectors are very limited, but the price (tax) on $\mathrm{CO}_{2}$ in non-ETS sectors would need to increase to $74.9 € / \mathrm{tCO}_{2}$ for a $25 \%$ target and to 243.4 $€ / \mathrm{tCO}_{2}$ for a $40 \%$ target. These prices are not only the highest of the four scenarios considered but also extremely high per se.

Finally, Table 3 shows the general results for a reduction of $30 \%$ (the level that the EU could achieve by 2020) in $\mathrm{CO}_{2}$ emissions when the figures are broken down according to different perspectives (general, by sectors and energy-related). As can be seen from the bottom part of the table, a $30 \%$ overall reduction in emissions requires different reductions from ETS and non-ETS sectors depending on the scenarios selected. Furthermore, the results show that variables such as utility, GDP, consumption and investment fall, whatever policy design is used. Utility drops by $0.5 \%$ in the CED scenario and by an interval of between 0.6 and $1.6 \%$ in the others. In this model, utility is the best indicator for the loss of welfare, but it must be stressed that the model does not take into account future benefits of mitigation policies and that the utility function does not incorporate the environmental quality variable as an argument. ${ }^{15}$

15 Recent literature on the appropriate discount rate uses a utility function in which not only consumption but also environmental goods matter (Gollier 2010). 
Table 3 General impacts of a $30 \%$ reduction in total $\mathrm{CO}_{2}$ emissions for scenarios (\%)

\begin{tabular}{lcccc}
\hline & CED & ED & POD & PED \\
\hline General (\%) & & & & \\
$\quad$ Utility & -0.5 & -0.6 & -1.6 & -0.7 \\
GDP & -0.6 & -0.8 & -1.6 & -0.8 \\
Private consumption & -0.5 & -0.5 & -1.2 & -0.6 \\
$\quad$ Investment & -1.2 & -1.4 & -2.5 & -1.5 \\
Sectoral output (\%) & & & & \\
$\quad$ Agriculture & -1.3 & -1.6 & -3.3 & -1.8 \\
Industry & -2.1 & -2.4 & -3.8 & -2.5 \\
Transport & -1.1 & -1.2 & -2.1 & -1.3 \\
$\quad$ Services & -0.7 & -0.8 & -1.4 & -0.8 \\
Energy consumption (\%) & & & & \\
$\quad$ Coal & -55.6 & -45.0 & -9.5 & -40.4 \\
$\quad$ Oil & -18.7 & -23.2 & -37.6 & -25.0 \\
Gas & -16.9 & -18.0 & -26.0 & -18.7 \\
$\quad$ Electricity & -7.4 & -6.9 & -6.6 & -6.8 \\
Emissions (\%) & & & & \\
$\quad$ Total emissions & -30.0 & -30.0 & -30.0 & -30.0 \\
Emissions ETS & -43.9 & -33.9 & -7.0 & -30.0 \\
Emissions NO-ETS & -19.0 & -26.9 & -48.5 & -30.0 \\
\hline
\end{tabular}

The drop in GDP for a 30\% reduction in $\mathrm{CO}_{2}$ emissions ranges from 0.6 to $1.6 \%$. This reflects falling trends in consumption and investment since public spending and the foreign trade deficit are constant. The fall in investment is due to lower returns originated by a drop in the prices of capital and labour relative to energy prices (and $\mathrm{CO}_{2}$ prices). Note also that although the drop in GDP is greater than the drop in utility, in this static model it is not possible to reflect how future economic growth will be affected by lower levels of investment.

Table 3 also reveals the effects on the economic structure, with the data aggregated under Agriculture, Industry, Transport and Services. The results show a shift of activity, for all scenarios, towards the Service sector. That shift is most pronounced for the distribution with the biggest overall impact (POD). This is a consequence of the way in which the possibilities of substitution in the output and utility functions are modelled. The service sector has a lower impact given that its economic activity is less $\mathrm{CO}_{2}$ intensive. Moreover, its economic weight is enormous (accounting for $65 \%$ of consumption and $45 \%$ of output) and hence the general reduction in the other macroeconomic variables is partly offset.

Other outcomes that highlight differences between scenarios are the respective impacts on energy consumption. For example, the CED scenario induces a change that is to some extent proportional to the carbon content of each fuel used for energy: coal consumption is reduced by $55.6 \%$, oil by $18.7 \%$, gas by $16.9 \%$ and electricity by $7.4 \%$. As we move away from this "ideal" scenario of variation in the energy mix the cost of reducing emissions increases. Hence the energy mix resulting from the POD distribution explains why this policy alternative is so expensive: the drop in the consumption of coal (the "dirtiest" fuel) is just $9.5 \%$, and the burden of achieving the emission reduction is shifted onto oil (37.6\%) and gas (26\%). 


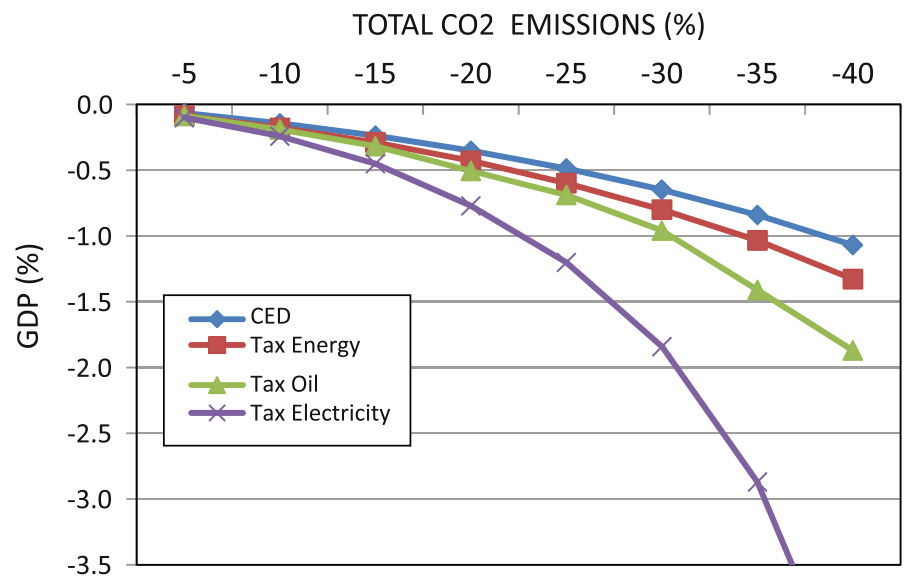

Fig. 4 Mitigation costs for different scenarios in non-ETS sectors

\subsection{General results for different taxes on non-ETS sectors}

In this sub-section we consider how the cost of achieving targets would change if a tax on energy, oil or electricity were used instead of a carbon tax in non-ETS sectors. As argued above, this change in "taxable income" is quite usual due to information and political difficulties in the real world (Pearce op cit). ${ }^{16}$ Note that now the non-ETS sectors will be taxed on something other than their level of carbon use, which could lead to quantifiable cost differences in meeting the targets established.

Figure 4 shows the results for the different scenarios compared to the CED scenario. It is clear that when the extent by which $\mathrm{CO}_{2}$ emission taxes are replaced by other related taxes increases, mitigation costs also increase. For a total reduction in $\mathrm{CO}_{2}$ of $30 \%$, GDP drops by $0.80 \%$ when the tax implemented is a tax on energy instead of a carbon tax.

A tax on oil also increases the cost of achieving the target. This is especially true in the case of higher emission reductions; for a $10 \%$ reduction in emissions the cost in terms of GDP is $0.19 \%$, i.e. 1.3 times greater than for a tax on $\mathrm{CO}_{2}(0.14 \%)$, but for a $40 \%$ reduction the cost is 1.7 times higher (1.07\% versus $1.87 \%)$. The point made in Sect. 3 about the positive probability of having to increase reduction targets also applies here. For the case of the tax on electricity the fall in GDP is significant. For a $10 \%$ reduction in emissions, the cost in terms of GDP is 1.7 times higher $(0.24 \%)$ than for a carbon tax, while for a $40 \%$ reduction it is 4.3 times higher (4.6\%).

The effect of each tax on non-ETS sectors is illustrated in Fig. 5 for each source in the energy mix. Note that in the CED scenario the level of consumption of each

\footnotetext{
16 Other studies such as Baranzini et al. (2000) also refer to "the widening gap between the political discourse and the policy practice" in the EU regarding carbon taxes. Neuhoff (2008) reminds us how in the 1990s the European Commission attempted to implement a European carbon tax but encountered strong opposition from industry and many Member States. In the case of the USA, Parry and Pizer (2007) clearly refer to strong political opposition to the setting up of new taxes.
} 
Fig. 5 Energy consumption (\%) for different scenarios in non-ETS sectors

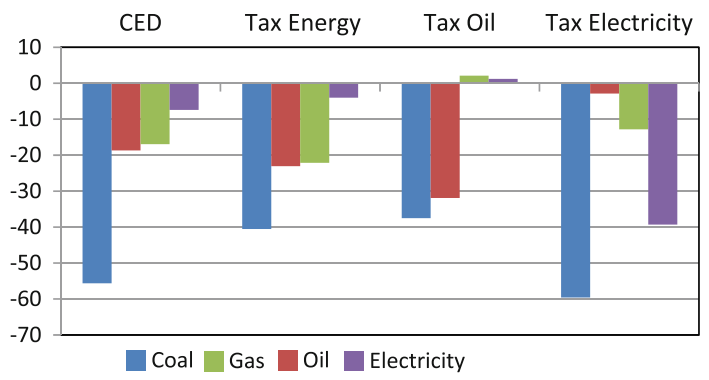

source is reduced by an amount proportional to its carbon content while a tax on energy reduces consumption of all three sources (fossil fuels) by amounts that are more similar to one another. A tax on oil brings consumption down by a substantial $31 \%$ and transfers energy requirements so that other sources, particularly gas, are less affected. The option that takes us furthest away from the optimum energy mix is the tax on electricity. This policy alternative would impose a reduction in electricity consumption of $39.2 \%$. In this case the consumption of coal drops by $59 \%$ and the consumption of gas by $12.8 \%$. This policy measure is the most expensive of all those analysed, since it fails to fully account for the role that low-carbon technologies can play in producing electricity.

The important lesson to be learned from these simulations is that is crucial to select a good policy design for climate policies that affects non-ETS sectors. Choosing the wrong instrument or policy can substantially increase the cost of fighting global warming. Our simulations also show that although substantial reductions in $\mathrm{CO}_{2}$ emissions can be achieved in the non-ETS part with the use of a tax on electricity, mitigation costs may be up to four times the quantity generated with a tax on $\mathrm{CO}_{2}$. This result is in line with what we have learned from economic theory. The best tax is one that levies emissions directly as they are the cause of the negative external effects for the economy. Any deviation from this rule will produce higher mitigation costs. The quantitative knowledge of how great that deviation can be is highly illustrative.

\section{Concluding remarks}

This paper argues that global warming is an important environmental problem with many economic implications and presents an analysis of the policy context in which the EU has to design effective instruments to deal with CC. The policy that we study is a combination of two instruments: the emissions trading scheme that is already in place in Europe (EU ETS) for sectors included so far in the system, and a $\mathrm{CO}_{2}$ tax (or other taxes) for the remaining sectors of the economy. The output of this policy is computed using an AGE model for the Spanish economy.

The first part of the paper analyses four scenarios depending on the criteria used to share the mitigation effort between ETS and non-ETS sectors (CED, ED, PED 
and POD). The results show that the cost of reducing emissions differs substantially depending on how the policies for effort sharing are designed. In the cost efficient distribution of efforts (CED scenario) we calculate that (for a mitigation target of 20\%) ETS sectors should undertake $68 \%$ of the effort while the non-ETS sector should be responsible for the remaining $32 \%$ only. The rationale behind this result is that mitigation is relatively cheaper in ETS sectors than in non-ETS ones due to the carbon content of the technologies used in these sectors. This result is a clear empirical illustration of what economic theory shows: cost-effective distribution implies that marginal abatement costs are equalised between sectors. Other criteria for distributing these efforts, e.g. by output (POD), proportionally to the real share of emissions (PED) or in an egalitarian manner (ED) are not cost-efficient. In fact, the further the distribution of the mitigation burden between ETS and non-ETS sectors deviates from the CED scenario, the greater the mitigation costs become.

Although the CED scenario is the ideal criteria for sharing out effort, an egalitarian rule (ED scenario) can be an "easy" proposal to defend on political grounds, and the same applies for proportional emission distribution (PED). Finally, the output basedcriteria (POD) may sound less "real" but it can be an alternative when policy makers decide to take care of some sectors. We presume that the most likely scenario would be the one based on emission as the cost-effective distribution scenario is probably more difficult to defend politically. However, we are fairly sure that some sectors will lobby for an output-based scenario. In any case the comparisons between them are revealing as they show that a policy design that is not cost-effective generates heavy losses for the economy as a whole.

The second part of the paper considers the possibility that the "taxable income" may be changed due to information and political difficulties. That is, that instead of a tax on $\mathrm{CO}_{2}$ for non-ETS sectors, one of the following three substitute instruments is used: a tax on energy, a tax on oil or a tax on electricity. This is not unusual in the real world. In a situation like this, the results show that none of the three options is cost-efficient. Moreover, the greater the extent to which $\mathrm{CO}_{2}$ emission taxes are replaced by other related taxes the more the mitigation cost increases. For a $20 \%$ mitigation target the tax on electricity generates the highest cost (close to $0.8 \%$ of GDP), followed by the tax on oil $(0.5 \%)$ and the tax on energy, which is relatively close to the cost effective scenario (CED). Note that although it is unlikely that any policy maker would tax electricity to reduce $\mathrm{CO}_{2}$ emissions, quantifying the potential range of costs that would result from choosing the "wrong" policy makes the likelihood of its implementation still lower. Economic incentives are a very powerful tool for reducing pollution but can also be very distorting if not well designed.

Finally, at least four lines for further research can be suggested. First, other important costs such as transaction or enforcement costs could be analysed, although these are relatively difficult to measure (Krutilla 1999; Heyes 2000). These expenditures will increase in different proportions depending on the instrument selected. Second, following Goulder and Parry (2008), other criteria such as equity or political feasibility could be incorporated into the analysis, highlighting the trade-off that one faces when having to choose among instruments. Third, it would be interesting to extend the analysis to incorporate the possibility envisaged in the Kyoto Protocol of buying emission credits abroad instead of making mitigation efforts domestically (known as 
Project-based Mechanisms ${ }^{17}$ ). This extension would probably enable a reduction in the cost of mitigation. And finally, as policy instruments are rarely implemented without some degree of overlapping, the problems that this might generate in different policy contexts could be explored. In this case, although some positive interactions should be expected, it is likely that overall compliance costs will increase, as Del Río (op cit) shows.

Open Access This article is distributed under the terms of the Creative Commons Attribution License which permits any use, distribution and reproduction in any medium, provided the original author(s) and source are credited.

\section{Appendices}

\begin{tabular}{lll} 
Indices & & \\
\hline Label & Entries & Description \\
\hline $\mathrm{j}, \mathrm{jj}$ & $1, \ldots, \mathrm{J}$ & Sectors, Intermediate Inputs or Goods \\
$\mathrm{e}$ & Coal, Oil, Gas & Fossil Fuels \\
\hline
\end{tabular}

\begin{tabular}{ll}
\multicolumn{2}{l}{ Parameter } \\
\hline Label & Description \\
\hline$\tau_{j}^{L}$ & Tax rate on labour, sector $\mathrm{j}$ \\
$\tau_{j}^{P}$ & Tax rate on capital, sector $\mathrm{j}$ \\
$\tau_{j}^{C}$ & Tax rate on consumption, good $\mathrm{j}$ \\
$\tau_{*}^{T}$ & Tax rate on specific energy-related goods (energy, oil and electricity) \\
$T$ & Transfers between consumers and government \\
$\alpha_{e}$ & $\mathrm{CO}_{2}$ emission coefficients for fuel and for producers \\
$\gamma_{e}$ & $\mathrm{CO}_{2}$ emission coefficients for fuel and for a representative consumer \\
$\sigma$ & Elasticity of substitution between inputs \\
\hline
\end{tabular}

\begin{tabular}{ll} 
Variables & \\
\hline Nombre & Descripción \\
\hline$Y_{j}$ & Output of sector $\mathrm{j}$ \\
$Y_{j, j j}^{I D}$ & Intermediate demand for input $\mathrm{jj}$ in sector $\mathrm{j}$ \\
$Y_{j}^{D}$ & Domestic demand for good $\mathrm{j}$ \\
$Y_{j}^{T S}$ & Total supply of good j \\
$Y_{j}^{T D}$ & Total demand for good $\mathrm{j}$ \\
$M_{j}$ & Imports of good $\mathrm{j}$ \\
$X_{j}$ & Exports of good $\mathrm{j}$ \\
\hline
\end{tabular}

\begin{tabular}{ll} 
Variables & \\
\hline Nombre & Descripción \\
\hline$K_{j}$ & Demand for capital of sector $\mathrm{j}$ \\
$L_{j}$ & Demand for labour of sector $\mathrm{j}$ \\
$U$ & Utility of representative consumer \\
$C_{j}$ & Private consumption of good j \\
$G_{j}$ & Public consumption of good j
\end{tabular}

\footnotetext{
17 These are foreseen under the Kyoto Protocol together with the emissions trading and are: (1) the Clean Development Mechanism (CDM) and (2) the Joint Implementation (JI).
} 


\begin{tabular}{ll} 
Variables & \\
\hline Nombre & Descripción \\
\hline $\mathrm{S}$ & Savings \\
$I_{j}$ & Investment in sector j \\
$P_{j}$ & Equilibrium market price of good j \\
$P_{K}$ & Equilibrium market price of capital \\
$P_{L}$ & Equilibrium market price of wages \\
$P_{X}$ & Equilibrium real exchange rate price of foreign goods \\
$P_{I}$ & Equilibrium market price of investment \\
$P_{E}$ & ${\mathrm{Equilibrium} \mathrm{market} \mathrm{price} \mathrm{of} \mathrm{CO}_{2} \text { permits in ETS sectors }}_{E^{E T S}} \mathrm{CO}_{2}$ emissions in ETS sectors \\
$E^{P}$ & $\mathrm{CO}_{2}$ emissions by producers \\
$E^{C}$ & $\mathrm{CO}_{2}$ emissions by representative consumer \\
$E$ & $\mathrm{Total} \mathrm{CO}_{2}$ permits in the ETS sectors
\end{tabular}

Table A1 Output, consumption and emissions in Spain

\begin{tabular}{|c|c|c|c|c|c|c|c|c|}
\hline & & \multirow{2}{*}{$\begin{array}{l}\text { Symmetric } \\
\text { input-output } \\
\text { Table (SIOT) } \\
\text { codes }\end{array}$} & \multicolumn{2}{|l|}{ Output } & \multicolumn{2}{|c|}{ Final consumption } & \multicolumn{2}{|c|}{$\mathrm{CO}_{2}$ emissions } \\
\hline & & & $(\mathrm{M} €)$ & $(\%)$ & $(\mathrm{M} €)$ & $(\%)$ & $\left(\mathrm{KtCO}_{2}\right)$ & $(\%)$ \\
\hline 1 & Agriculture \& fishing & $1,2,3$ & 26,758 & $(3.8 \%)$ & 4358 & $(1.7 \%)$ & 12,727 & $(5.5 \%)$ \\
\hline 2 & Coal mining & 4 & 1542 & $(0.2 \%)$ & 40 & $(0.0 \%)$ & 315 & $(0.1 \%)$ \\
\hline 3 & $\begin{array}{l}\text { Crude oil \& gas } \\
\text { extraction }\end{array}$ & 5 & 130 & $(0.0 \%)$ & 0 & $(0.0 \%)$ & 165 & $(0.1 \%)$ \\
\hline 4 & $\begin{array}{l}\text { Extraction of } \\
\text { other minerals }\end{array}$ & 6.7 & 1782 & $(0.3 \%)$ & 18 & $(0.0 \%)$ & 364 & $(0.2 \%)$ \\
\hline 5 & Food industry & $12,13,14,15,16$ & 46,260 & $(6.5 \%)$ & 27,438 & $(11.0 \%)$ & 5602 & $(2.4 \%)$ \\
\hline 6 & Textile industry & $17,18,19$ & 12,554 & $(1.8 \%)$ & 9684 & $(3.9 \%)$ & 1683 & $(0.7 \%)$ \\
\hline 7 & Paper industry & $20-22$ & 13,858 & $(2.0 \%)$ & 3415 & $(1.4 \%)$ & 3828 & $(1.7 \%)$ \\
\hline 8 & Oil refining industry & 8 & 7563 & $(1.1 \%)$ & 2991 & $(1.2 \%)$ & 655 & $(0.3 \%)$ \\
\hline 9 & Chemical industry & $23-24$ & 21,065 & $(3.0 \%)$ & 2935 & $(1.2 \%)$ & 16,089 & $(7.0 \%)$ \\
\hline 10 & $\begin{array}{l}\text { Ceramic, cement and } \\
\text { glass industry }\end{array}$ & $36-38$ & 12,736 & $(1.8 \%)$ & 2773 & $(1.1 \%)$ & 25,870 & $(11.2 \%)$ \\
\hline 11 & Metal industry & $29-30$ & 22,913 & $(3.2 \%)$ & 41 & $(0.0 \%)$ & 19,104 & $(8.3 \%)$ \\
\hline 12 & Machinery industry & $31-35$ & 31,104 & $(4.4 \%)$ & 3744 & $(1.5 \%)$ & 2494 & $(1.1 \%)$ \\
\hline 13 & Other industries & $25-28$ & 36,245 & $(5.1 \%)$ & 7463 & $(3.0 \%)$ & 22,615 & $(9.8 \%)$ \\
\hline 14 & Electricity & 9 & 11,335 & $(1.6 \%)$ & 4287 & $(1.7 \%)$ & 51,698 & $(22.5 \%)$ \\
\hline 15 & Natural gas & 10 & 861 & $(0.1 \%)$ & 413 & $(0.2 \%)$ & 517 & $(0.2 \%)$ \\
\hline 16 & Water distribution & 11 & 2457 & $(0.3 \%)$ & 1096 & $(0.4 \%)$ & 275 & $(0.1 \%)$ \\
\hline 17 & Construction & 40 & 100,059 & $(14.1 \%)$ & 8186 & $(3.3 \%)$ & 2346 & $(1.0 \%)$ \\
\hline 18 & Land transport & 45.46 & 21,818 & $(3.1 \%)$ & 5394 & $(2.2 \%)$ & 11,629 & $(5.1 \%)$ \\
\hline 19 & Maritime transport & 47 & 1583 & $(0.2 \%)$ & 139 & $(0.1 \%)$ & 3166 & $(1.4 \%)$ \\
\hline 20 & Air transport & 48 & 3320 & $(0.5 \%)$ & 646 & $(0.3 \%)$ & 4019 & $(1.7 \%)$ \\
\hline 21 & Transport services & 49,50 & 20,395 & $(2.9 \%)$ & 5752 & $(2.3 \%)$ & 1035 & $(0.4 \%)$ \\
\hline 22 & Commercial services & $\begin{array}{l}41-44,51-56,58 \\
62-63,68-71\end{array}$ & 219,791 & $(31.1 \%)$ & 145,537 & $(58.2 \%)$ & 5780 & $(2.5 \%)$ \\
\hline 23 & $\begin{array}{l}\text { Non commercial } \\
\text { services }\end{array}$ & $\begin{array}{l}39,57,59-61, \\
64-67\end{array}$ & 91,005 & $(12.9 \%)$ & 13,888 & $(5.5 \%)$ & 2334 & $(1.0 \%)$ \\
\hline- & Consumers & - & - & - & - & - & 35,678 & $(15.5 \%)$ \\
\hline & Total & & 707,134 & $(100 \%)$ & 250,238 & $(100 \%)$ & 229,985 & $(100 \%)$ \\
\hline
\end{tabular}

${ }^{1}$ The "Other Industries" according to Spanish CNAE classification groups together the following sectors: motor vehicles, other transport material, furniture, recycling, other non-metal mineral products Source INE (2002) and own work 
Table A2 Elasticities of substitution in production, trade and consumption

\begin{tabular}{lll}
\hline$\sigma^{Y}$ & Material inputs and Capital-Labour-Energy & 0 \\
$\sigma^{K L E}$ & Capital-Labour and Energy (ETS, Electricity, No ETS) & $1,1.25,0.75$ \\
$\sigma^{K L}$ & Capital and Labour & 1 \\
$\sigma^{E}$ & Electricity and Fossil Fuels (ETS, Electricity, No ETS) & $0.5,0.75,0.25$ \\
$\sigma^{F}$ & Coal, Oil and Gas (ETS, Electricity, No ETS) & $1,1.25,0.75$ \\
$\sigma^{A}$ & Domestic and imported goods & 3 \\
$\sigma^{T}$ & Domestic goods and exports & 2 \\
$\sigma^{C}$ & Consumption of energy and non energy goods & 0.5 \\
$\sigma^{C E}$ & Consumption of energy goods & 1 \\
$\sigma^{C B}$ & Consumption of non energy goods & 1 \\
\hline
\end{tabular}

Source MIT-EPPA (Babiker et al. 2001)

\section{References}

Aldy JE, Krupnick AJ, Newell RG, Parry, IWH, Pizer WA (2009) Designing climate mitigation policy. RFF discussion paper, 08-16-REV

Alesina AF, Passarelli F (2010) Regulation versus taxation. NBER working paper no. 16413

Ansuategi A, Galarraga I (2009) Carbon pricing as an effective instrument of climate policy: searching for an optimal policy instrument. Rivista di Politica Economica, VII-IX

Arto I, Gallastegui MC, Ansuategi A (2009) Accounting for early action in the European Union Emission Trading Scheme. Energy Policy 37:3194-3924

Babiker MH, Mayer M, Wieng I, Hyman R (2001) The MIT emissions prediction and policy analysis EPPA model. MIT Global Change Joint Program, 71, Cambridge, MA

Baranzini A, Goldemberg J, Speck S (2000) A future for carbon taxes: survey. Ecol Econ 32:395-412

Baumol WJ, Oates WE (1971) The use of standards and prices for protection of the environment. Swedish J Econ 73:42-54

Baumol WJ, Oates WE (1988) The theory of environmental policy, 2nd edn. Cambridge University Press

Böhringer C, Rosendahl KE (2010) Green promotes the dirtiest: on the interaction between black and green quotas in energy markets. J Regul Econ 37:316-325

Boots M (2003) Green certificates and carbon trading in the Netherlands. Energy Policy 31(1):43-50

COD (2008) Proposal for a decision of the European Parliament and of the Council on the Effort of Member States to reduce their greenhouse gas emissions to meet the community's greenhouse gas emission reduction commitment up to 2020. 2008/0014 (COD)

Dellink R, Hofkes M, van Ierland E, Verbruggen H (2004) Dynamic modelling of pollution abatement in a CGE framework. Econ Model 21(6):965-989

Del Río P (2009) Interactions between climate and energy policies: the case of Spain. Clim Policy 9: 119-138

Del Río P, Labandeira X, Linares P (2009) La interacción del sistema europeo de comercio de emisiones con otros instrumentos de política. Papeles de Economía Española 121:211-224

Eurostat (2005) Energy, transport and environment. European Statistic Office, Luxemburg

Faehn T, Gómez-Plana A, Kverndokk S (2009) Can a carbon permit system reduce Spanish unemployment? Energy Econ 31(4):595-604

Gallastegui MC, Galarraga I (2010) La Unión Europea Frente al Cambio Climático: El Paquete de Medidas sobre Cambio Climático y Energía (20-20-20). In: Becker F, Cazorla LM, Martínez-Simancas J (eds) Tratado de Energías Renovables. Iberdrola-Thomson-Aranzadi

Gallastegui MC, Iñarra E, Prellezo R (2002) Bankruptcy of fishing resources: the Northern European anglerfish fishery. Mar Resour Econ 17(4):291-307

Gollier C (2010) Ecological discounting. J Econ Theory 145:812-829 
González-Eguino M (2010) Modelización de los coste de mitigación de emisiones: el caso de un mercado de permisos de emisión para España. Trimestre Económico 305(1):185-218

Goulder LH, Parry I (2008) Instruments choice in environmental policy. Resource for the future. Discussion Paper 08-07, Washington, DC

Goulder LH, Stavins RN (2010) Interactions between state and federal climate change policies. Foundazione Eni Enrico Mattei Working Papers, 487

Goulder LH, Parry I, Williams RC III, Burtraw DT (1999) The cost-effectiveness of alternative instruments for environmental protection in a second-best setting. J Public Econ 72:329-360

Green KP, Hayward SF, Hassett KA (2007) Climate change: cap vs. Taxes. Environmental Policy Outlook, American Enterprise Institute for Public Policy Research, AEI, no. 2, June

Hahn RW (1989) Economic prescriptions for environmental problems: how the patient followed the doctor's orders. J Econ Perspect 3(2):95-114

Hahn RW (2000) The impact of economics on environmental policy. J Environ Econ Manag 39:375-399

Hauser T, Bradley R, Childs B, Werkman J, Heilmayr R (2008) Leveling the carbon playing field: international competition and US climate policy design. Peterson Institute for International Economics, World Resource Institute, Washington, DC

Hayashi F (1982) Tobin's q, rational expectations and optimal investment rule. Econometrica 50:213-224

Heyes A (2000) Implementing environmental regulation: enforcement and compliance. J Regul Econ 17:107-129

Hoel M (1990) Efficient international agreements for reducing emissions of $\mathrm{CO}_{2}$. University of Oslo Working papers. Department of Economics

Hoel M, Karp LS (2002) Taxes versus quotas for a stock pollutant. Resour Energy Econ 24:367-384

Hourcade JC, Neuhoff K, Demailly D, Sato M (2008) Differentiation and dynamics of EU ETS industrial competitiveness impacts. Climate Strategies Papers

INE (2002) Cuentas Económicas. Instituto Nacional de Estadística, Madrid

Kolstad CD, Toman M (2005) The economics of climate policy. In: Mäler KG, Vincent J (eds) Handbook of environmental economics, vol 3. Elsevier, Amsterdam, pp 1561-1618

Krutilla K (1999) Environmental policy and transactions cost. In: van den Bergh (ed) Handbook of environmental and resource economics. Edward Elgar, Cheltenham

Labandeira X, Rodríguez M (2007) Wide and narrow approaches to national climate policies: a case study for Spain. Clim Policy 10(1):51-69

Linares P, Santos FJ, Ventosa M (2008) Interactions of carbon reduction and renewable support policies in electricity markets: a review of existing results and some recommendations for a coordinated regulation. Clim Policy 8(4):377-394

Manresa A, Sancho F (2005) Implementing a double dividend: recycling ecotaxes towards lower labour taxes. Energy Policy 33(12):1577-1585

Morthorst PE (2003) National environmental targets and international emission reduction instruments. Energy Policy 31:73-83

Newell RG, Stavins RN (2003) Cost heterogeneity and potential savings from market-based policies. J Regul Econ 23:43-59

Nordhaus WD (2008) The challenge of global warming: economic models and environmental policy. Yale University Press, New Haven

OECD (2009) The cost-effectiveness of climate change mitigation policy instruments. In: The economics of climate change mitigation: policies and options for global action beyond 2012. Paris

Parry I, Pizer B (2007) Combating global warming: is taxation or cap-and-trade the better strategy for reducing greenhouse emissions. Regulation 30(3):18-22

Pearce D (2006) The political economy of an energy tax: the United Kingdom's climate change levy. Energy Econ 28:149-158

Rutherford T, Paltsev S (2000) GTAP-EG: incorporating energy statistics into GTAP format. WP, University of Colorado

Shoven J, Whalley J (1992) Applying general equilibrium. Cambridge University Press

Sijm J (2003) Interaction of the EU emissions trading directive with climate policy instruments in the Netherlands. Policy brief INTERACT project. ECN, Amsterdam

Sijm J (2005) The interaction between the EU emissions trading scheme and national energy policies. Clim Policy 5:79-89

Sijm J (2007) Options for post-2012 EU burden sharing and EU ETS allocation. ECN and MNP Working paper 
Springer U (2003) The market for tradable GHG permits under the Kyoto protocol: a survey of model studies. Energy Econ 25:527-551

Stern N (2008) The economics of climate change. Am Econ Rev 98(2):1-37

Tietenberg T (1990) Economic instruments for environmental regulation. Oxf Rev Econ Policy 6(1):17-34

Tirole J (2010) From Pigou to extended liability: on the optimal taxation of externalities under imperfect financial markets. Rev Econ Stud 77(2):697-729

Uzawa H (2003) Economic theory and global warming. Cambridge University Press. ISBN:052182386-2

Weitzman ML (1974) Prices versus quantities. Rev Econ Stud 41:477-491

Weyant JP (ed) (1999) The costs of the Kyoto protocol: a multi-model evaluation. Energy J 20:1-398 